\title{
PENGARUH LATIHAN PERIODE PERSIAPAN UMUM PON TERHADAP PERUBAHAN DAYA TAHAN KARDIORESPIRASI ATLET KONTINGEN BAYANGAN PON XIX 2016 KONI SULAWESI SELATAN
}

\author{
Muh Thahir , \\ Jurusan Fisioterapi Polteknik Kesehatan Makassar
}

\begin{abstract}
ABSTRAK
Pengaruh latihan periode persiapan umum PON terhadap perubahan daya tahan kardiorespirasi atlet kontingen bayangan PON XIX 2016 KONI Sulawesi Selatan. Penelitian ini bertujuan mempelajari pengaruh latihan periode persiapan umum PON terhadap perubahan daya tahan kardiorespirasi atlet kontingen bayangan PON XIX 2016 KONI Sulawesi Selatan. Penelitian ini bersifat observasional dengan rancangan studi prospektif. Popolasi dalam penelitian ini adalah atlet kontingen bayangan PON XIX 2016 KONI Sulawesi Selatan kelompok cabang olahraga permainan yang berjumlah 129 atlet. Sampel yang diambil sebanyak 100 atlet dengan kriteria inklusi : berumur antara 17-26 tahun, rutin mengikuti latihan, tidak sedang cedera, mengikuti pre test dan post test. Penelitian ini menggunakan pengukuran daya tahan kardiorespirasi sebelum dan setelah mengikuti latihan periode persiapan umum PON XIX 2016 yang dilakukan selama 8 minggu. Data dianalisis melalui uji wilcoxon. Instrumen tes yang digunakan pada penelitian ini adalah three minutes step test untuk mengukur daya tahan kardiorespirasi atlet kontingen bayangan PON XIX 2016 KONI Sulawesi Selatan. Hasil penelitian menunjukkan bahwa ada perbedaan daya tahan kardiorespirasi atlet kontingen bayangan PON XIX 2016 sebelum dan sesudah mengikuti latihan periode persiapan PON. Berdasarkan uji Wilcoxon $\alpha=0,000(\rho<0,05)$ menunjukkan bahwa ada pengaruh yang signifikan antara latihan periode persiapan umum PON terhadap perubahan daya tahan kardiorespirasi atlet kontingen bayangan PON XIX 2016 ditandai dengan penurunan denyut nadi dengan menggunakan three minutes step test. Dapat disimpulkan Bahwa latihan periode persiapan umum PON berpengaruh terhadap perubahan daya tahan kardiorespirasi atlet kontingen bayangan PON XIX 2016 KONI Sulawesi Selatan.
\end{abstract}

Keywords: Latihan periode persiapan Umum PON, Daya tahan Kardiorespirasi, atlet kontingen bayangan PON XIX 2016.

\section{PENDAHULUAN}

Aspek latihan merupakan salah satu yang menentukan pencapaian prestasi atlet dalam olahraga, seperti latihan kondisi fisik untuk mempertahankan fisik menghadapi stres-stres fisik dalam latihan dan pertandingan. Latihan kondisi fisik harus mengacu kepada suatu program latihan yang dilakukan secara sistematis,berencana, dan progresif yang tujuannya ialah untuk meningkatkan kemampuan fungsional dari seluruh sistem tubuh agar demikian prestasi atlet akan meningkat (Kardjono, 2008). Latihan kondisi fisik mencakup beberapa komponen antara lain : Kekuatan otot (strenght), daya tahan kardiorespirasi (general endurance), kelentukan (flexibility), kecepatan (speed), daya tahan otot (muscular endurance) dan sebagainya (Sajoto, 1990).

Daya tahan kardiorespirasi menjadi unsur terpenting karena daya tahan kardiorespirasi diperlukan untuk menghindari kelelahan berlebihan sehingga atlet mampu menjalani waktu pertandingan yang lebih lama. Untuk itu,setiap atlet membutuhkan daya tahan kardiorespirasi yang baik dalam memperoleh hasil yang optimal dan mampu tampil prima sejak awal hingga akhir pertandingan.

Latihan daya tahan menyebabkan adaptasi pada sistem kardiorespirasi dan neuromuskular dengan meningkatkan pengantaran oksigen dari atmosfir ke mitokondria dan memungkinkan regulasi yang lebih ketat akan metabolisme otot. Adaptasi ini akan mempengaruhi peningkatan dalam performa daya tahan sehingga memungkinkan atlet untuk berlatih lebih lama untuk intensitas latihan tertentu atau berlatih pada intensitas latihan tinggi dengan durasi tertentu (Gormley, 2005).

Latihan daya tahan aerobik yang teratur memicu perubahan-perubahan metabolik di dalam serat oksidatif,yaitu serat yang terutama direkrut selama olahraga aerobik.Sebagai contoh, jumlah mitokondria dan jumlah kapiler yang menyalurkan darah ke serat-serat tersebut meningkat. Otot-otot yang telah beradaptasi dapat menggunakan $\mathrm{O} 2$ secara efisien dan karenanya lebih tahan melakukan aktivitas berkepanjangan tanpa kelelahan (Sherwood, 2011).

Untuk atlet yang telah terlatih performa daya tahan dapat dicapai dengan Highintensity Interval Training (HIT). Riset terbatas yang memeriksa perubahan pada aktivitas enzim otot pada atlet terlatih setelah HIT, tidak menemukan adanya perubahan dalam aktivitas enzimatik glikolitik atau oksidatif, meskipun terdapat perubahan yang signifikan dalam performa daya tahan, meski begitu peningkatan dalam kapasitas penyangga otot skeletal bisa menjadi salah satu mekanisme yang bertanggung jawab terhadap peningkatan performa daya tahan (Laursen \& Jenkins, 2002).

Latihan daya tahan dapat menghasilkan peningkatan jumlah kapiler tiap serat otot, namun sepertinya sedikit berpengaruh atau 
bahkan tidak berpengaruh terhadap pengembangan ukuran otot, dimana biasanya dengan pelatihan resistensi yang berat akan menyebabkan peningkatan ukuran serat otot dan juga kekuatannya, namun tidak ada peningkatan oksidatif pada otot. Penelitian selanjutnya memperlihatkan bahwa otot yang terlatih daya tahannya (endurance-trained) dapat lebih efektif menggunakan trigliserida, glukosa dan asam lemak bebas sebagai sumber energi sedemikian rupa sehingga sumber energi utama otot tersebut pada waktu exercise berubah dari karbohidrat menjadi lemak (Wilmore \& Costill, 2004).

Berdasarkan latar belakang tersebut, maka menarik perhatian penulis untuk meneliti pengaruh latihan kondisi fisik terhadap peningkatan daya tahan kardiorespirasi atlet kontingen bayangan PON XIX 2016 KONI Sulawesi Selatan.

\section{BAHAN DAN METODE}

\section{Lokasi dan Waktu}

Penelitian ini dilaksanakan di KONI Sulsel dan Kampus UNM pada tanggal 18 Agustus sampai dengan 18 Oktober 2016.

\section{Populasi dan Teknik Sampel}

Populasi dalam penelitian ini adalah semua atlet kontingen bayangan PON XVII KONI Sulawesi Selatan yang mengikuti latihan periode persiapan umum PON sebanyak 129 atlet kelompok cabang olahraga permainan. Sampel dalam penelitian ini adalah sebagian dari atlet kontingen bayangan PON XVIII KONI Sulawesi Selatan yang mengikuti latihan periode persiapan umum PON yang memenuhi kriteria inklusi. Sampel yang diambil sebanyak 100 atlet dengan kriteria inklusi : berumur antara 17-26 tahun, rutin mengikuti latihan, tidak sedang cedera, mengikuti pre test dan post test.

\section{Instrumen Pengumpul Data}

Alat atau instrumen yang digunakan untuk mempermudah proses pengumpulan data dalam penelitian ini adalah three minutes step test untuk mengukur daya tahan kardiorespirasi. Serta hasil data yang diperoleh melalui pengukuran daya tahan kardiorespirasi. Pengukuran daya tahan kardiorespirasi di KONI Sulsel.

\section{Analisa Data}

Data yang terkumpul diolah melalui program komputer dengan analisa data sebagai berikut: pengaruh latihan periode persiapan umum PON terhadap perubahan daya tahan kardiorespirasi atlet kontingen bayangan PON XIX 2016 KONI Sulawesi Selatan. Oleh karena itu maka uji hipotesis yang digunakan adalah Uji Wilcoxon dengan menggunakan program komputer.

\section{HASIL}

\section{Analisis Univariat}

Tabel 5.1 menunjukkan bahwa jenis kelamin atlit Sulsel maju II sebagian besar Laki-laki (52\%), cabang olahraga yang terbanyak adalah basket (27\%) dan paling sedikit adalah tennis lapangan (4\%).

\section{Analisis Bivariat}

Tabel 5.2 menunjukkan adanya perubahan daya tahan kardiorespirasi atlet sebelum dan sesudah pemberian latihan periode persiapan PON. Pada pada pre test atlet dengan kategori excellent 34 , good 33 , above average 16 , average 7 , below average 6 , poor 4. Pada post test excellet 42, good 32 , above average 15 , average 3 , below average 2 , poor 3 , very poor 3 .

Tabel 5.3 menunjukkan perubahan daya tahan kardiovaskuler, dimana post test lebih kecil dari pre test. tabel di atas menunjukkan bahwa pada pre test, rata-rata daya tahan kardiovaskuleradalah 89,46 $\pm 17,627$ turun menjadi $86,00 \pm 20,030$ pada post test.

Tabel 5.4 menunjukkan hasil uji normalitas data dengan menggunakan uji Kolmogorov-Smirnov pada nilai daya tahan kardiovaskuler sebelum latihan dan sesudah latihan. Hasil uji menunjukkan nilai sebesar 0,088 dengan nilai $p=0,055(p>0,05)$ sebelum latihan dan nilai sebesar $0,000(p<$ $0,05)$ sesudah latihan yang berarti data terdistribusi tidak normal pada nilai daya tahan kardiovaskuler yang diperoleh oleh semua Subjek. Hal ini menunjukkan tidak adanya homogenitas sampel berdasarkan nilai daya tahan kardiovaskuler sebelum latihan dan sesudah latihan.

Tabel 5.4 menunjukkan perubahan Daya Tahan Kardiovaskuler, dimana post test lebih Kecil dari pre test. Tabel di atas menunjukkan bahwa pada pre test, rata-rata daya tahan kerdiovaskuler adalah 89,46 , turun menjadi 86,00 pada post test.

\section{PEMBAHASAN}

Latihan periode persiapan atlet kontingen bayangan PON KONI Sulsel memberikan pengaruh yang bermakna terhadap daya tahan kardiovaskuler atlet melalui uji wilcoxon dengan nilai $\rho 0,000$. Pada penelitian ini menunjukkan bahwa terjadi peningkatan daya tahan kardiovaskuler yang bermakna. Daya tahan kardiovaskuler 
sebelum dan setelah latihan menunjukkan ada pengaruh yang bermakna dengan nilai $p 0,000$ pada tingkat kepercayaan 95\%. Pada penelitian ini menunjukkan bahwa terjadi peningkatan daya tahan kardiovaskular yang bermakna.

Perubahan yang paling nampak terlihat setelah melakukan training adalah peningkatan kemampuan melakukan latihan sub maksimal dalam waktu yang lama dan peningkatan kapasitas aerobik maksimal seseorang $\left(\mathrm{VO}_{2} \mathrm{max}\right)$. Derajat perbaikan pada endurance sub maksimal dan $\mathrm{VO}_{2} \max$ bervariasi setelah pemberian program training. Beberapa orang dapat mengalami perbaikan $\mathrm{VO}_{2} \max$ sebesar $20-30 \%$ sebagai konsekuensi dari program training tetapi beberapa orang juga dapat mengalami perubahan $\mathrm{VO}_{2}$ max yang kecil (kurang dari $5 \%$ ). Secara umum peningkatan rata-rata $\mathrm{VO}_{2}$ Max dari program training bervariasi antara 15 $-20 \%$.

Dari penelitian Green et.al dijelaskan bahwa sebagian besar perbaikan terjadi selama 4 minggu pertama dari program training. Green et.al telah mengobservasi lakilaki yang aktif melakukan program training dimana menunjukkan $15,6 \%$ terjadi peningkatan $\mathrm{VO}_{2}$ max secara normal pada lakilaki yang aktif melakukan aktivitas bersepeda selama 2 jam perhari dengan lima sampai enam kali seminggu selama 8 minggu. $\mathrm{VO}_{2}$ max merupakan faktor utama untuk menentukan intensitas latihan atau kecepatan langkah yang dapat dilakukan secara terusmenerus. $\mathrm{VO}_{2} \max$ biasa dinyatakan dalam berat badan, dalam mililiter oksigen yang dikonsumsi perkilogram permenit $(\mathrm{mL} / \mathrm{kg}$ permenit). $\quad \mathrm{VO}_{2} \max$ bergantung pada transportasi oksigen, kapasitas ikatan oksigen dalam darah, fungsi jantung, kapabilitas difusi oksigen dan oksidatif potensial di otot. Dengan program endurance training maka lebih banyak oksigen dapat dikirim dan dikonsumsi sehingga pada orang-orang yang tidak terlatih dapat mengalami peningkatan rata-rata $\mathrm{VO}_{2} \max$ sebesar $20 \%$ atau lebih setelah mengikuti program training (Kisner, 2002).

Kenaikan cardiac output pada kontraksi isotonik ini dapat mencapai nilai 35 liter/menit, yaitu jumlah yang sebanding dengan pemakaian $\mathrm{O}_{2}$ yang meningkat. Kenaikan cardiac output dalam hal ini terjadi oleh kenaikan stroke volume maupun denyut jantung. Penambahan denyut jantung disebabkan oleh rangsangan simpatik adrenergik, oleh berkurangnya tonus syaraf vagus, dan refleks Bainbridge.
Latihan daya tahan menghasilkan penurunan denyut nadi selama istirahat dan peningkatan stroke volume istirahat. Penurunan denyut nadi istirahat merupakan hasil dari lebih banyaknya inhibisi SA Node oleh nervus vagus, penurunan denyut nadi dipercaya berhubungan dengan peningkatan volume darah, sebagai tambahan, penelitian telah menunjukkan volume darah meningkat sekitar $500 \mathrm{ml}$ selama 8 hari training. Adaptasi ini memungkinkan atlit terlatih menghasilkan peningkatan cardiac output lebih besar dan mencapai cardiac output selama latihan (Fox, et all, 2003).

Perubahan yang terjadi adalah denyut nadi istirahat pada atlit yang terlatih akan mengalami penurunan karena terjadi penurunan impuls simpatetik yang disertai dengan penurunan level Norefinefrin dan efinefrin serta terjadi penurunan denyut nadi arteri yang bersifat sekunder terhadap perubahan biokimia dalam otot dan level asitilkolin, norefinefrin dan efinefrin di dalam atrium, terjadi suatu peningkatan tonus parasimpatetik yang bersifat sekunder terhadap penurunan tonus simpatetik. Selain hal tersebut diatas perubahan lain yang terjadi adalah peningkatan volume darah dan hemoglobin yang memfasilitasi kapasistas pengiriman oksigen dalam sistem kardiovaskuler.

Cardiac output dipengaruhi oleh pengalian antara kecepatan denyut jantung dengan stroke volume. Banyak pula faktorfaktor yang mempengaruhi baik stroke volume maupun denyut jantung. Sedangkan tahanan darah perifer total terutama ditentukan oleh rangsangan susunan saraf autonom, hormonhormon yang beredar dan penumpukan lokal dari berbagai zat kimia.

Aliran darah ke otot skelet yang sedang istrahat jumlahnya hanya $2-4 \mathrm{ml} / 100 \mathrm{gr} /$ menit. Ketika berkontraksi malahan jumlah ini lebih menurun sampai berhenti oleh karena penekanan yang dialami pembuluh darah dalam otot akibat kontraksi. Pada kontraksi lebih dari $10 \%$ dari tegangan maksimal, sudah mulai penekanan terhadap pembuluh darah, sedangkan jika tegangan kontraksi otot mencapai $70 \%$ nilai maksimal, aliran darah sama sekali terhenti. Tetapi diantara masa kontraksi, jumlah aliran darah ke dalam otot meningkat sampai 30 kali lebih banyak.

Selain dari itu keadaan lokal disekitar pembuluh darah pada otot yang berkontraksi dapat mempertahankan adanya jumlah aliran darah yang banyak. Faktor-faktor yang berperan dalam hal ini adalah penurunan tekanan $\mathrm{O}_{2}$ dan kenaikan tekanan $\mathrm{CO}_{2}$ dalam 
jaringan dan penumpukan zat-zat yang menimbulkan vasodilatasi akibat metabolisme dalam otot, yang disebut "vasodilatasi metabolites".

\section{KESIMPULAN}

1. Pada pada pre test atlet dengan kategori excellent 34, good 33, above average 16 , average 7 , below average 6 , poor 4 .

2. Pada post test excellet 42 , good 32 , above average 15 , average 3 , below average 2 , poor 3 , very poor 3 .

3. Ada pengaruh latihan periode persiapan PON berpengaruh terhadap peningkatan daya tahan kardiorespirasi atlet kontingen bayangan PON

\section{SARAN}

1. Diharapkan kepada atlet-atlet kontingen bayangan PON XIX 2016 agar meningkatkan atau mempertahankan daya tahan kardiovaskulernya dengan melakukan latihan secara teratur dan terus menerus.

2. Pemeriksaan daya tahan kardiovaskuler dilakukan secara berkala setiap 3 bulan untuk memantau perubahan daya tahan kardiovaskuler atlet.

Tabel. 5.1

Karakteristik atlit kontingen bayangan PON XIX KONI Sulsel tahun 2016

\begin{tabular}{|c|c|c|}
\hline Karakteristik atlit & $\mathbf{n}$ & $\%$ \\
\hline $\begin{array}{l}\text { Jenis kelamin } \\
\text { a. Laki-laki } \\
\text { b. Perempuan }\end{array}$ & $\begin{array}{l}52 \\
48 \\
\end{array}$ & $\begin{array}{l}52 \\
48 \\
\end{array}$ \\
\hline Total & 100 & 100 \\
\hline \begin{tabular}{ll} 
& \multicolumn{1}{c}{ Cabang olahraga } \\
a. & Basket \\
b. Bulutangkis \\
c. Kriket \\
d. Sepakbola \\
e. Sepaktakraw \\
f. Tennis Lapangan \\
\end{tabular} & $\begin{array}{c}27 \\
13 \\
14 \\
18 \\
24 \\
4\end{array}$ & $\begin{array}{c}27 \\
13 \\
14 \\
18 \\
24 \\
4 \\
\end{array}$ \\
\hline Total & 100 & 100 \\
\hline
\end{tabular}

Sumber : Data Primer 2016

Tabel. 2

Kriteria daya tahan cardiorespirasi atlet kontingen bayangan PON XIX KONI Sulsel tahun 2016

\begin{tabular}{llcc}
\hline \multicolumn{1}{c}{ Kriteria daya ledak } & Pre test & Post test \\
\hline a. Excellent & 34 & 42 \\
b. Good & 33 & 32 \\
c. Above Average & 16 & 15 \\
d. Average & 7 & 3 \\
e. Below Average & 6 & 2 \\
f. Poor & 4 & 3 \\
g. Very Poor & 0 & 3 \\
\hline & Total & $\mathbf{1 0 0}$ & $\mathbf{1 0 0}$ \\
\hline
\end{tabular}

Sumber : Data Primer 2016

Tabel 3.

Deskripsi Nilai Rerata, Minimum, Maksimum dan Standar Deviasi (SD) Daya Tahan Kardiovaskuler Atlet Kontingen Bayangan PON XIX KONI Sulsel Sebelum dan Setelah Latihan Periode Persiapan Umum

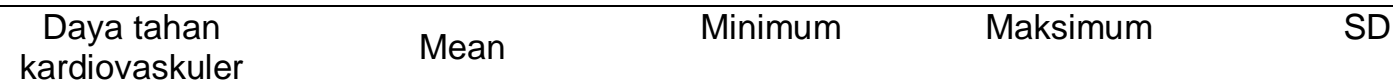




\begin{tabular}{lrrrr}
\hline Sebelum latihan & 89,46 & 46 & 137 & 17,627 \\
Setelah latihan & 86,00 & 34 & 152 & 20,030 \\
\hline
\end{tabular}

Sumber : Data Primer 2016

Tabel 4.

Hasil Uji Normalitas Data daya tahan kardiovaskuler atlet kontingen bayangan PON XIX KONI Sulawesi Selatan Tahun 2016

\begin{tabular}{lccccc}
\hline $\begin{array}{c}\text { Daya tahan } \\
\text { kardiovaskuler }\end{array}$ & $\mathrm{N}$ & Nilai Rerata & Standar Deviasi & $\begin{array}{c}\text { Kolmogor } \\
\text { ov- } \\
\text { Smirnov }\end{array}$ & $\mathrm{p}$ \\
\hline Sebelum Latihan & 100 & 89,46 & 17,627 & $\mathbf{0 , 0 8 8}$ & $\mathbf{0 , 0 5 5}$ \\
Sesudah Latihan & 100 & 86,00 & 20,030 & $\mathbf{0 , 1 3 1}$ & $\mathbf{0 , 0 0 0}$ \\
\hline
\end{tabular}

Sumber: data primer 2016

Tabel. 5

Distribusi Perubahan Daya tahan Kardiovaskuler atlit kontingen bayangan PON XIX KONI Sulsel Tahun 2016

\begin{tabular}{ccccc}
\hline $\begin{array}{c}\text { Daya Tahan } \\
\text { Kardiovaskuler }\end{array}$ & Mean & Minimum & Maksimum & SD \\
\hline Sebelum latihan & 89,46 & 46 & 137 & 17,627 \\
Setelah latihan & 86,00 & 34 & 152 & 20,030 \\
\hline
\end{tabular}

Sumber : Data Primer 2016

Tabel. 6

Pengaruh Latihan periode persiapan PON terhadap Perubahan Daya tahan Kardiovaskuler atlit kontingen bayangan PON XIX KONI Sulsel Tahun 2016

\begin{tabular}{ccc}
\hline Daya tahan Kardiovaskuer & Mean & $\mathrm{p}^{*}$ \\
\hline Sebelum latihan & $89,46 \pm 17,627$ & 0.000 \\
Setelah latihan & $86,00 \pm 20,030$ & \\
\hline
\end{tabular}

${ }^{*}$ Uji Wilcoxon

\section{DAFTAR PUSTAKA}

Arikunto S, 2002, Prosedur penelitian, Edisi Revisi V, Rineka Cipta, Jakarta

Ann Redgrave, 2008, Exercise Physiology In Special Population, Elseiver Limited, UK

Bompa, Tudor O, 1999, Periodozation Training for Sport. Ontorio Canada: York University

Bompa Tudor O, 2000, Total Training for Young Champions. Campaign: Human Kinetics

Caroline Kisner and Colby, 2002, Therapeutik Exercise Foundation and Technique, 5th edition. F A davies Company Philadhelpia, USA
Clare E. Milner, 2008, Functional Anatomy for Sport and Exercise, Milton Park, Abingdon, Oxon, New York, USA

Dahlan, Muhammad Sopiyudin. 2009. Statisitik untuk Kedokteran dan Kesehatan: Deskriptif, Bivariat, dan Multivariat, Dilengkapi Aplikasi dengan Menggunakan SPSS. Jakarta: Salemba Medika

David C. Nieman, 1990, Fittness and Sport Medicine, Polo Alto, California, USA

Depkes RI, 2002, Gizi Atlet Bola, Direktorat Jenderal Bina kesehatan Masyarakat Direktorat Gizi Masyarakat, Jakarta.

Fox, 1993, Human Physiology, Third Edition Grawn-hill company, New York USA

Fox, 2003, Human Physiology, Eight Edition Grawn-hill company, New York USA 
Fox, E.L. 1993. Sport Physiology. New York: CBS College Publishing.

Gerta Vrbová et all, 2008, Application of Muscle/Nerve Stimulation in Health and Disease, University College Medical School London, UK

Ganong William F, 2003, Review of medical Physiology. McGrawn-hill company, New York USA

Guyton \& Hall, 2006. Medical Physiology, $11^{\text {th }}$ ed.W.B Saunders Company, Philadelpia, Pennsylvania.

Ilhamjaya, Patellongi. 1999. Pengaruh Intensitas Latihan Fisik terhadap Keruskan Jaringan. Surabaya: Universitas Airlangga

John Gormley, 2005, Exercise therapy prevention and treatment of disease, Trinity College, UK

Karen M Birch et all, 2008, Exercise physiology in special population, Elsevier Limited, Philadelphia, USA

KONI Sulawesi Selatan, 2008, Laporan Kontingen PON XVII-2008 Provinsi Sulawesi Selatan, Makassar KONI Sulawesi Selatan

Lauralee Sherwood, 2011, Fisiologi Manusia dari Sel ke Sistem, Penerbit Buku kedokteran, EGC,

Matthew et all, 2003, A Comparison of Linear and Daily Undulating Periodized Programs With Equated Volume and Intensity for Local Muscular Endurance, Journal of Strength and Conditioning Research, 2003, 17(1), 82-87 National Strength \& Conditioning Association

Machfoedz, Ircham. 2009. Metodologi Penelitian Bidang Kesehatan, Keperawatan, Kebidnanan, Kedokteran. Yokyakarta: Penerbit Fitramaya

Michael J. Alter MS, 1996, 300 Teknik Peregangan Olahraga" PT Pustaka Karya Grafika Utama, Jakarta.

Notoatmojo, S. 2005, Metodologi Penelitian Kesehatan, Rineka Cipta, Jakarta
Nukhrawi Nawir, 2008, Perubahan Predominan Filamen Aktin dan Miosin Otot Skeletal pada Dosis Latihn Fisik Interval Anaerobik, Disertasi program disertasi Universitas Airlangga, Surabaya.

Nur Ichsan Halim, 2004, Tes dan pengukuran Kebugaran Jasmani, State University of Makassar Press, Makassar

Pearce, EC, 2000. Anatomi dan Fisiologi untuk paramedis. Penerbit PT. Gramedia Jakarta.

Program pascasarjana Unhas, 2006, Pedoman Penulisan Tesis dan Disertasi Edisi 4 Makassar, Universitas Hasanuddin

Program Pascasarjana Unhas. 2006. Pedoman Penulisan Tesis dan Disertasi Edisi 4. Makassar: Universitas Hasanuddin

Riwidikdo, Handoko. 2009. Statistik Kesehatan. Jogjakarta: Mitra Cendikia Press

Sadoso Sumosardjuno, 1987, Petunjuk Praktis Kesehatan Olahraga.PT Pustaka Karya Grafika Utama. Jakarta

Tácito P Souza-Junior et all, 2011, Strength and hypertrophy responses to constant and decreasing rest intervals in trained men using creatine supplementation, Journal of the International Society of Sports Nutrition 2011, 8:17http://www.jissn.com/content/8/1 $/ 17$

Valerie C Scanlon \& Tina Sanders, 2007, Essential Anatomy and Physiology, $5^{\text {th }}$ edition, $\mathrm{F} A$ davies Company Philadhelpia, USA

Walter R. Thompson, 2009, ACSM's Guidelines for Exercise Testing and Prescription, USA

Travel J. \& Simon D.Myofascial pain and Dysfunction: The trigger point 
Manual. Baltimore; Williams \& Wilkins.

Wheeler, A.H.. Myofascial Pain Disorders: Theory to Therapy.North Carolina, USA: Adis International, Charlotte Spine Center.2004

Willmore H.J and Costill I.D. Physiology of Sport and Exercise (2nd edition). Aucland.1999 